\title{
INVESTIGATION OF THE EFFECTIVENESS OF USING VIRTUAL REALITY AS A DISTRACTION TECHNIQUE IN CHILDREN DURING LOCAL ANESTHESIA INJECTION FOR EXTRACTION OF PRIMARY MANDIBULAR MOLARS
}

\author{
Mohammed Omran Hamed*, Mohamed Saber Elsherbini** and Samir Ali Elborolsy*
}

\begin{abstract}
Background: Local anesthesia injection for tooth extraction of primary molars is one among the causes of avoiding dental visits in children. Voice control and hand over mouth exercise are invasive and considered the least accepted techniques, a more accepted technique for children and their parents was needed.
\end{abstract}

Aim: To evaluate the efficacy of virtual reality (VR) distraction on dental anxiety and pain perception to local anesthesia injection in pediatric dental patients during primary teeth extraction.

Material and Methods: A prospective, parallel two arms randomized; clinical trial was performed on seventy-two children. Patients were (7-11) years old with unilateral carious nonrestorable mandibular primary first molars required local anesthesia (LA) for extraction. Group (A) received treatment wearing virtual reality (VR) device and Group (B) received treatment using tell, show and do behavior management technique. Anxiety levels were measured using heart rate (HR) measuring before and after the injection while pain perception was assessed immediately after the injection using the Face, Legs, Activity, Crying and CONSOL ability scale (FLACC) and Facial Image Scale (FIS).

Results: There was a statistically significant difference in heart rate mean values between both groups. Virtual reality (VR) distraction group showed better results in lowering anxiety during dental treatment.

Conclusion: Virtual reality (VR) device could be advocated for reducing anxiety to local anesthetic injection in children undergoing extraction of primary teeth.

KEYWORDS: Dental Anxiety, Distraction, Pain Perception, Virtual Reality.

\footnotetext{
* Lecturer, Oral and Maxillofacial Surgery Department, Faculty of Dentistry, Beni-Suef University, Egypt.

** Lecturer, Pedodontics Department Faculty of Dentistry, Assiut University, Egypt.
} 


\section{INTRODUCTION}

Pain is an unpleasant sensory and emotional experience associated with actual or potential tissue injury. (1) In dentistry, untreated carious teeth are the main reason for pain in each adult and young patient. (2) To alleviate this pain and to successfully perform the intended treatment, local anesthesia (LA) administration is a broadly used method, which also triggers some fear and anxiety in pediatric patients. ${ }^{(3)}$. Clearly worldwide fear of needles is common in children, which makes them apprehensive, anxious and worried during their first dental visits. ${ }^{(4)}$ Furthermore, pain and anxiety experienced and felt in dental clinics remain in an individual's memory. ${ }^{(5)}$

Distraction or redirection is believed to divert attention and may modulate pain perception. ${ }^{(6}$, 7) In 1965, the gate control theory (GCT) of pain was introduced by Melzack and Wall ${ }^{(8)}$. It had been the primary theory to introduce the concept that pain isn't merely the result of a linear process that begins with the stimulation of pain pathways within the peripheral nervous system and ends with the experience of pain within the central nervous system. ${ }^{(7,8)}$

Virtual reality (VR) is considered a new technology that refers to a human-computer interface using 3D head-mounted displays with a good field-of-view. Additionally, it works in such a way that diverts the child's attention and takes them into a virtual world that distracts them from the real world thus reducing both pain and stress resulting from dental treatments. Also, VR distraction involves multiple senses such as sight, sound, and kinesthetic sensations to distract the patient from the dental environment socially and emotionally which significantly reduces the child's anxiety. ${ }^{(9,10)}$ Moreover, a study that was done by Niharika et al. ${ }^{(11)}$, showed that VR distraction could be a better distraction strategy for children with elevated dental fear and anxiety. Based on these studies, the VR distraction is a potential tool for pain and anxiety alleviation and reduction especially when it is related to the fear of needles.

Hence, the purpose of the present study is to determine the efficacy of virtual reality glasses (VRG) in reducing injection pain and anxiety related to local anesthesia in pediatric dental patients during primary teeth extraction.

\section{MATERIALS AND METHODS}

Study design: The study was a prospective, parallel two arms, randomized, clinical trial.

\section{Study population and informed consent:} The study involved patients who visited the dental clinic of Faculty of Dentistry, Beni-Suef University for emergency dental treatment. Written informed consent was obtained from each caregiver, confirming his/ her complete approval to participate in the study.

Seventy-two healthy children 7-11 years old had been selected to participate in this study. Inclusion criteria: Patient's cooperative potential has been assessed according to Frankl Behavior scale ${ }^{(12)}$ by observation of the interaction with the child and only children whose behaviors were positive and definitely positive were selected, healthy classified ASA I, according to the American Society of Anesthesiologists (ASA) physical status classification. Patients whose parents agreed to take part in the study were clinically and radiographically tested to ensure that they met the inclusion criteria and were scheduled for a single dental visit for extraction of primary mandibular first molar under local anesthesia.

Exclusion criteria: Children had chronic disease, history of previous hospitalization or surgery, autism, neurological behavior disorders such as attention deficit and hyperactivity disorder or learning disabilities, mental retardation, hearing, visual and speech disorders, and any problem 
associated with the site of wear of the VR glass were excluded from the study.

Blinding: The operator and the patients were not blinded to treatment technique, on the other hand the statistician, was blinded to the two treatment groups.

Intervention: Patients who met the inclusion criteria underwent a preliminary screening as well as a complete medical and dental history. 72 participants were randomly divided into two equal groups of 36 patients. Group (A) received mandibular nerve block injections (MNBIs) using distraction with VRG while taking the injection. Group (B) received mandibular nerve block injections (MNBIs) adopting the Tell, Show, and Do behavior management technique before local anesthetic injection without wearing VRG.

Eligible patients undergone a single-visit treatments in which L.A. was delivered with a conventional syringe. The L.A. administered for extraction was 1.8 to $3.6 \mathrm{~mL}$ of $2 \%$ lidocaine with epinephrine $12.5 \mathrm{mg} / \mathrm{mL}$ (1: 80,000). Topical anesthesia was used before the L.A. injection. All treatment procedures were performed by the same pediatric dentist. All the patients were scheduled for performing the planned procedures in the morning after having their usual breakfast by two hours.

During dental treatment, the pediatric dentist explained the procedure in simple terms using tell-show-do technique including measuring HR. For another visit, an introduction to the VRG to choose out of cartoon movies by showing their posters on an A4 sheet. (Fig.1) Cartoon series were Tom and Jerry, Looney Tunes, Minions, Penguins, Race, Sponge Bob and Oscar. Children were given few minutes to get accustomed to the VRG. For the second group other behavior management techniques were used as tell-show-do, positive reinforcement and conventional distraction (deep breath or breath counting).
The XQISIT virtual reality glasses used during the dental procedures blocked the visual field of the child completely and had headphones to deliver the sound and connected to a player capable of playing audiovisual files connected though mobile phones. (Fig.2)

\section{Pain and anxiety Assessment:}

Pain and anxiety were evaluated subjectively using The Face, Legs, Activity, Cry, CONSOL ability scale (FLACC), the Facial Image Scale (FIS) and by using physiological measure (Heart rate).The FLACC scale is a measurement used to assess pain for children between the ages of 2 months and 7 years or individuals that are unable to communicate their pain. The scale is scored in a range of $0-10$ with 0 representing no pain. The scale

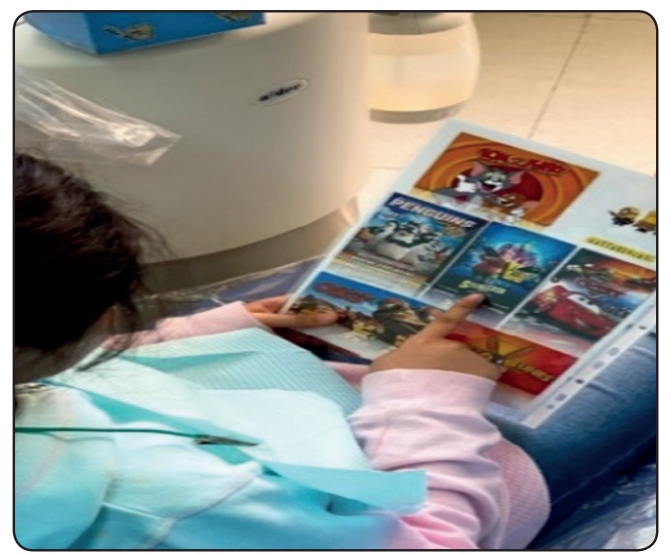

Fig. (1) Choose out of cartoon movies posters on an $A_{4}$ sheet

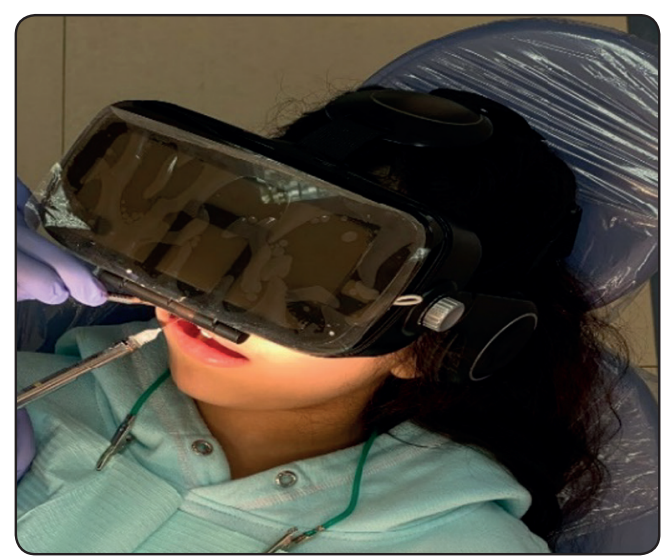

Fig. (2): VRG used during the dental procedures 
has five criteria, which are each assigned a score of 0,1 or . $^{(13)}$ (Table 1 ) Report about the anxiety after the injection was evaluated on the Facial Image Scale (FIS) (Fig. 3). The facial image scale (FIS) is a series of five faces that range from extremely happy to extremely unhappy ${ }^{(14)}$. The patients were asked to point to the face they most resembled at the time. The most positive affect face is given a value of one, while the most negative affect face is given a value of five.

Anxiety levels were measured using heart rate measuring before and after the injection using just your finger at the wrist of the patient by lightly pressing the index and middle fingers of one hand on the opposite wrist, just below the base of the thumb. After that count the number of beats in 15 seconds, and multiply by four.

\section{Examiner reliability:}

For standardization, two investigators were trained separately to measure pain using the FLACC scale. The interclass correlation coefficient was used to assess inter-examiner reliability (ICC). ${ }^{(15)}$

\section{Statistical analysis:}

The data were presented by frequency and percentage for qualitative data and graphical presentation for tables using a SPPS/Mac statistical package was used to analyze the data.

\section{RESULTS}

Seventy-two participants were enrolled in the present study, 38 boys and 34 girls, randomly distributed in the two treatment groups. To evaluate the effectiveness of virtual reality device in distracting children during the local anesthesia injection, comparison was made between participants who wore VR device (group A) and without VR device (group B).

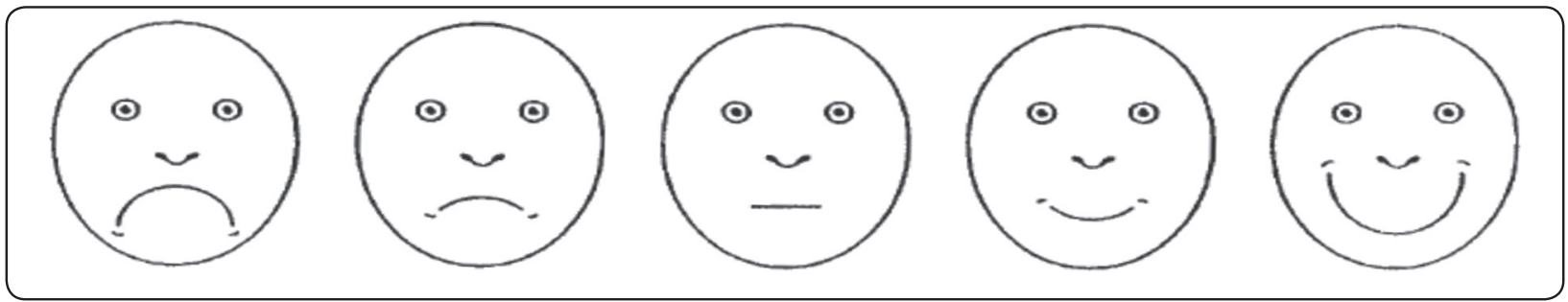

Fig. (3): The Facial Image Scale (FIS)

Table 1: The FLACC scale or Face, Legs, Activity, Cry, CONSOL ability scale

\begin{tabular}{|c|c|c|c|}
\hline Criteria & Score 0 & Score 1 & Score 2 \\
\hline Face & $\begin{array}{l}\text { No particular expression } \\
\text { or smile }\end{array}$ & $\begin{array}{l}\text { Occasional grimace or frown, withdrawn, } \\
\text { uninterested }\end{array}$ & $\begin{array}{l}\text { Frequent to constant quivering } \\
\text { chin, clenched jaw }\end{array}$ \\
\hline Legs & Normal position or relaxed & Uneasy, restless, tense & Kicking, or legs drawn up \\
\hline Activity & $\begin{array}{l}\text { Lying quietly, normal } \\
\text { position, moves easily }\end{array}$ & Squirming, shifting, back and forth, tense & Arched, rigid or jerking \\
\hline Cry & No cry (awake or asleep) & Moans or whimpers; occasional complaint & $\begin{array}{l}\text { Crying steadily, screams or } \\
\text { sobs, frequent complaints }\end{array}$ \\
\hline $\begin{array}{l}\text { CONSOL } \\
\text { ability }\end{array}$ & Content, relaxed & $\begin{array}{l}\text { Reassured by occasional touching, } \\
\text { hugging or being talked to, distractible }\end{array}$ & Difficult to console or comfort \\
\hline
\end{tabular}


Table 2: showing that mean HR before treatment in group (B) was $(80.11 \pm 10.37)$ as compared to group $(\mathrm{A})$ was $(81.78 \pm 12.89)$ these values represented no significant differences $(\mathrm{P}=0.283)$. Whereas mean HR after treatment in group $\mathrm{B}$ was $(94 \pm 11.37)$ is significantly high compared to group A (85.44 \pm 11.35$)$. Similarly, mean FLACC scale scores in group B was $(4.58 \pm 2.49)$ which represents significantly higher than group A (1.47 \pm $2)$. And mean FIS scale scores in group B was (3.25 \pm 1.12 ) which represents significantly higher than group A $(1.81 \pm 1)$.

Table 3: comparing the response of boys and girls in Group (A) Mean HR before treatment in boys was $(83.81 \pm 12.892)$ as compared to girls which was $(78.93 \pm 12.559)$ these values represent no significant difference $\mathrm{P}=0.114$. Whereas the mean HRafter treatment in boys was $(88 \pm 9.1)$ as compared to girls $(81.87 \pm 13.28)$ was significantly different, boys higher than girls $\left(\mathrm{P}=0.023^{*}\right)$.
Whereas the FLACC scale scores in boys was (1.33 $\pm 1.44)$ and girls was $(1.67 \pm 2.62)$ these values represented no significant difference in both gender $\mathrm{P}=0.491$. FIS scale scores in boys was $(1.57 \pm 0.74)$ and girls $(2.13 \pm 1.22)$, girls represented higher values than boys and a significant difference was found $(\mathrm{P}=0.018 *)$

Table 4: comparing the response of boys and girls in Group B. Mean HRbefore treatment in boys was $(81.71 \pm 8.86)$ as compared to girls $(77.87 \pm 11.97)$ these values represented no significant differences $\mathrm{P}=0.121$ and the mean HR after treatment in boys was $(92.95 \pm 9.91)$ as compared to girls $(95.47 \pm$ 92.95) showed no significant differences in both gender $\mathrm{P}=0359$. Whereas the FLACC scale scores in boys and girls were $(4.10 \pm 2.16)$ and $(5.27 \pm$ 2.79) respectively. These values demonstrated that girls were significantly different than boys $\mathrm{P}=0$. 049. FIS scale scores in boys were $(2.90 \pm 1.17)$ and girls $(3.73 \pm 0.87)$ girls showed significant statistical difference than boys $\mathrm{P}=0.002$.

Table (2): Comparing Heart rate, FLACC scale and FIS scale scores in the two groups

\begin{tabular}{|c|c|c|c|c|c|}
\hline Type of procedure & $\mathrm{N}$ & Mean & Std. Deviation & $\mathrm{t}$-value & P-value \\
\hline Group A - HR Before & 36 & 81.78 & 12.894 & \multirow{2}{*}{-1.082} & \multirow{2}{*}{0.283} \\
\hline Group B - HR Before & 36 & 80.11 & 10.367 & & \\
\hline Group A - HR After & 36 & 85.44 & 11.350 & \multirow[t]{2}{*}{6.184} & \multirow{2}{*}{$0.000^{*}$} \\
\hline Group B - HR After & 36 & 94.00 & 11.373 & & \\
\hline Group A - FLACC & 36 & 1.47 & 2.007 & \multirow{2}{*}{12.948} & \multirow{2}{*}{$0.000 *$} \\
\hline Group B - FLACC & 36 & 4.58 & 2.494 & & \\
\hline Group A - FIS & 36 & 1.81 & 1.002 & \multirow{2}{*}{15.264} & \multirow{2}{*}{$0.000 *$} \\
\hline Group B - FIS & 36 & 3.25 & 1.123 & & \\
\hline
\end{tabular}

Table (3): Comparison of responses of boys and girls in group A

\begin{tabular}{|c|c|c|c|c|c|c|}
\hline Type of procedure & Gender & $\mathrm{N}$ & Mean & Std. Deviation & t-value & p-value \\
\hline \multirow[t]{2}{*}{ Group A - HR Before } & Boys & 20 & 83.81 & 12.892 & \multirow[t]{2}{*}{1.599} & \multirow[t]{2}{*}{0.114} \\
\hline & Girls & 16 & 78.93 & 12.559 & & \\
\hline \multirow[t]{2}{*}{ Group A - HR After } & Boys & 20 & 88.00 & 9.074 & \multirow[t]{2}{*}{2.330} & \multirow[t]{2}{*}{$0.023 *$} \\
\hline & Girls & 16 & 81.87 & 13.276 & & \\
\hline \multirow[t]{2}{*}{ Group A - FLACC } & Boys & 20 & 1.33 & 1.443 & \multirow[t]{2}{*}{-.692} & \multirow[t]{2}{*}{0.491} \\
\hline & Girls & 16 & 1.67 & 2.617 & & \\
\hline \multirow[t]{2}{*}{ Group A FIS } & Boys & 20 & 1.57 & 0.737 & \multirow[t]{2}{*}{-2.425} & \multirow[t]{2}{*}{$0.018 *$} \\
\hline & Girls & 16 & 2.13 & 1.224 & & \\
\hline
\end{tabular}


Table (4): Comparison of responses of boys and girls in group B

\begin{tabular}{|c|c|c|c|c|c|c|}
\hline Type of procedure & Gender & $\mathrm{N}$ & Mean & Std. Deviation & t-value & p-value \\
\hline \multirow{2}{*}{ Group B -HR Before } & Boys & 18 & 81.71 & 8.863 & \multirow[t]{2}{*}{1.568} & \multirow[t]{2}{*}{0.121} \\
\hline & Girls & 18 & 77.87 & 11.965 & & \\
\hline \multirow{2}{*}{ Group B -HR After } & Boys & 18 & 92.95 & 9.909 & \multirow{2}{*}{-.924} & \multirow[t]{2}{*}{0.359} \\
\hline & Girls & 18 & 95.47 & 13.193 & & \\
\hline \multirow{2}{*}{ Group B - FLACC } & Boys & 18 & 4.10 & 2.162 & \multirow{2}{*}{-2.007} & \multirow[t]{2}{*}{$0.049^{*}$} \\
\hline & Girls & 18 & 5.27 & 2.791 & & \\
\hline \multirow{2}{*}{ Group B - FIS } & Boys & 18 & 2.90 & 1.165 & \multirow[t]{2}{*}{-3.294} & \multirow[t]{2}{*}{$0.002 *$} \\
\hline & Girls & 18 & 3.73 & .868 & & \\
\hline
\end{tabular}

${ }^{*} p<0.05$ significant

\section{DISCUSSION}

Apart from identifying dental anxiety in children, one of the main rules of any pediatric dentist is to implement strategies to treat children in a way that incorporates a positive attitude in them for potential dental visits ${ }^{(16)}$. The unusual and often disturbing sights, sounds, and sensations of the dental operatory trigger anxiety in children during dental care ${ }^{(17)}$. Patients often complain that the local anesthetic injection is the only painful sensation they experience, and fear of injection has been identified as a principal factor in deciding whether or not to seek dental care ${ }^{(18)}$.

Pediatric dentists have used non-pharmacological and pharmacological (general anesthesia and conscious sedation) behavior guidance techniques to reduce children's fear of LA injection for many years ${ }^{(19)}$. According to McCaul and Mallot ${ }^{(20)}$, distracting a child from an unpleasant stimulus can lead to a reduction in pain perception.

The present study was conducted to assess the effectiveness of virtual reality (VR) in distracting children during local anesthesia injection for teeth extraction in non-restorable primary molars and to compare the findings with others who were managed with Tell, Show, and Do (TSD) behavior management technique.

Dental anxiety has been measured in literature using a variety of subjective and objective methods $^{(21,22)}$. Self-reporting questionnaires, as well as other numerical or pictorial scales, are used to assess anxiety ${ }^{(18)}$. Picture tests are thought to be suitable for testing dental anxiety in children because they are straightforward and easy to understand ${ }^{(16)}$.

Numerous picture tests have been used in various studies to assess anxiety during dental procedures. ${ }^{(23,24)}$ The facial image scale (FIS) has been selected to assess anxiety before and after administration of local anesthesia as very simple emoticons are used in selection.

Since dental anxiety is a multi-factorial model with psychological, perceptive, and physiological components, relying on a single parameter to quantify it may not be reliable ${ }^{(25)}$. The subjective and objective pain of children in the current study was assessed using FACES and FLACC, respectively, for more accurate outcomes, and pain and anxiety in children were measured using a physiologic test (pulse rate).

The FLACC scale has been shown to have outstanding validity and reliability for pain assessment in young children when used objectively. ${ }^{(26,27)}$ 
The study included 72 children (38 boys, 34 girls) and the mean age and standard deviation (SD) for group A and group B were 8.4 \pm 1.379 and $8.6 \pm$ 1.322 , respectively with equal numbers of children allocated to the two study groups.

The results showed that physiological measurement of pulse rate revealed a positive association between mean scores measured before and after distraction with VRG. Pulse rates at baseline showed no absolute difference between the two groups. On the other hand, HR in group B was higher than that in group A after treatment and the difference was significant between the two groups. Similar findings were found in studies by Sullivan et al. ${ }^{(28)}$, Mitrakul $^{(29)}$, and Agarwal ${ }^{(30)}$.

However, Nuvvula et al. ${ }^{(31)}$ and Al Khotani ${ }^{(32)}$ found no substantial difference in pulse rates between the audiovisual and control groups, which contradicts the revealed results and these might be due to the different methods used to measure the pulse rate or the variations in the ages of the participants in each study.

Furthermore, mean FLACC scale scores in group $\mathrm{B}$ was significantly higher than group $\mathrm{A}$, and mean FIS scale scores in group B was also, significantly higher than group A. Comparable results from the study conducted by Khandelwal et al who found that audio-visual distraction is superior to TSD in treating 5-8-year-old anxious children ${ }^{(33)}$.

Moreover, VR distraction with i-theatreTM eyeglasses decreased observer-rated dental anxiety in eight-year-old children during restorative dental care, according to AlKhotaniet al. ${ }^{(32)}$.Shah et al. found that pre-procedural gaming caused a substantial difference in hemodynamic parameters in 60 children aged 5 to 10 years old in a cross-over randomized trial ${ }^{(34)}$.

Agarwal ${ }^{(30)}$ and EL Sharkawi ${ }^{(35)}$ indicated pain relief during topical anesthetic application and LA with the use of audiovisual distraction. On contrary, VR diversion was found to be ineffective in reducing anxiety levels in children undergoing invasive dental procedures by Sullivan et al. ${ }^{(28)}$. This variance could be as a result of the different procedures performed and the diverse durations of the dental visits.

When the findings of this study were analyzed in terms of gender, no statistical significance was found for the FLACC scale scores. On the other hand, HR, and FIS score between boys and girls were statistically significant different. Girls showed higher levels of dental anxiety than their boys' counterparts.

In a Swedish study conducted by Holst et al, the results revealed comparable finding to the current

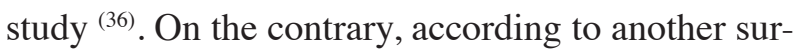
vey. The investigators found that males had higher levels of dental anxiety than females. However, Kilinçet al. ${ }^{(37)}$ discovered that there is no substantial difference in relation to gender in their research.

The results of this study advocates the use of virtual reality (VR) device for reducing anxiety during local anesthetic injection in children undergoing extraction of primary teeth.

\section{REFERENCES}

1. Pain terms: a list with definitions and notes on usage. Recommended by the IASP Subcommittee on Taxonomy. Pain. 1979 Jun;6(3):249

2. Nomura LH, Bastos JL, Peres MA. Dental pain prevalence and association with dental caries and socioeconomic status in schoolchildren, Southern Brazil, 2002. Braz Oral Res. 2004 Apr-Jun;18(2):134-40.

3. Bedi R, Sutcliffe P, Donnan PT, McConnachie J. The prevalence of dental anxiety in a group of 13- and 14-year-old Scottish children. Int J Paediatr Dent. 1992 Apr;2(1):17-24.

4. Kaur R, Jindal R, Dua R, Mahajan S, Sethi K, Garg S. Comparative evaluation of the effectiveness of audio and audiovisual distraction aids in the management of anxious pediatric dental patients. J Indian Soc Pedod Prev Dent. 2015 Jul-Sep;33(3):192-203. 
5. Folayan MO, Fatusi A. Effect of psychological management techniques on specific item score change during the management of dental fear in children. J Clin Pediatr Dent. 2005 Summer;29(4):335-40.

6. Simon JF, Peltier B, Chambers D, Dower J. Dentists troubled by the administration of anesthetic injections: long-term stresses and effects. Quintessence Int. 1994 Sep;25(9):641-6.

7. Galik E, Fukudo S, Tanaka Y, et al. Gate Control Theory of Pain. Encyclopedia of Behavioral Medicine. 2013;832834.

8. Melzack R, Wall PD. Pain mechanisms: a new theory. Science. 1965 Nov 19;150(3699):971-9.

9. Wismeijer AA, Vingerhoets AJ. The use of virtual reality and audiovisual eyeglass systems as adjunct analgesic techniques: a review of the literature. Ann Behav Med. 2005 Dec;30(3):268-78.

10. Slifer, K.J., Tucker, C.L. \& Dahlquist, L.M. Helping Children and Caregivers Cope with Repeated Invasive Procedures: How Are We Doing? Journal of Clinical Psychology in Medical Settings 9, 131-152 (2002).

11. Niharika P, Reddy NV, Srujana P, Srikanth K, Daneswari V, Geetha KS. Effects of distraction using virtual reality technology on pain perception and anxiety levels in children during pulp therapy of primary molars. J Indian Soc Pedod Prev Dent. 2018 Oct-Dec;36(4):364-369.

12. Frankl SN, Shiere FR, Fogels HR. Should the parent remain with the childin the dental operatory? J Dent Child 1962; 29:150 3

13. Voepel-Lewis T, Zanotti J, Dammeyer JA, Merkel S. Reliability and validity of the face, legs, activity, cry, consolability behavioral tool in assessing acute pain in critically ill patients. Am J Crit Care. 2010 Jan;19(1):55-61.

14. Buchanan H, Niven N. Validation of a Facial Image Scale to assess child dental anxiety. Int J Paediatr Dent. 2002 Jan;12(1):47-52.

15. Cicchetti, D.. "Guidelines, Criteria, and Rules of Thumb for Evaluating Normed and Standardized Assessment Instruments in Psychology." Psychological Assessment 6 (1994): 284-290.

16. Sadana G, Grover R, Mehra M, Gupta S, Kaur J, Sadana S. A novel Chotta Bheem-Chutki scale for dental anxiety determination in children. J Int Soc Prev Community Dent. 2016;6(3):200-205.
17. Hoge MA, Howard MR, Wallace DP, Allen KD. Use of video eyewear to manage distress in children during restorative dental treatment. Pediatr Dent. 2012 SepOct;34(5):378-82.

18. Kaufman E, Epstein JB, Naveh E, Gorsky M, Gross A, Cohen G. A survey of pain, pressure, and discomfort induced by commonly used oral local anesthesia injections. Anesth Prog. 2005 Winter;52(4):122-7.

19. Cianetti S, Paglia L, Gatto R, Montedori A, Lupatelli E. Evidence of pharmacological and non-pharmacological interventions for the management of dental fear in paediatric dentistry: a systematic review protocol. BMJ Open. 2017 Aug 18;7(8):e016043.

20. McCaul KD, Malott JM. Distraction and coping with pain. Psychol Bull. 1984 May;95(3):516-33.

21. Kime S, Wilson KE, Girdler NM. Evaluation of objective and subjective methods for assessing dental anxiety. J Disabil Oral Health 2010;11(2):69e72.

22. Pani SC, AlAnazi GS, AlBaragash A, AlMosaihel M. Objective assessment of the influence of the parental presence on the fear and behavior of anxious children during their first restorative dental visit. J Int Soc Prev Community Dent. 2016 Aug;6(Suppl 2):S148-52.

23. Venham LL. The effect of mother's presence of child's response to dental treatment. ASDC J Dent Child. 1979 May-Jun;46(3):219-25.

24. Wong DL, Baker CM. Pain in children: comparison of assessment scales. Pediatr Nurs. 1988 Jan-Feb;14(1):9-17.

25. Aartman IH, van Everdingen T, Hoogstraten J, Schuurs AH. Self-report measurements of dental anxiety and fear in children: a critical assessment. ASDC J Dent Child. 1998 Jul-Aug;65(4):252-8, 229-30.

26. Willis MH, Merkel SI, Voepel-Lewis T, Malviya S. FLACC Behavioral Pain Assessment Scale: a comparison with the child's self-report. Pediatr Nurs. 2003 May-Jun; 29(3):195-8.

27. Merkel S, Voepel-Lewis T, Malviya S. Pain assessment in infants and young children: the FLACC scale. Am J Nurs. 2002 Oct;102(10):55-8.

28. Sullivan C, Schneider PE, Musselman RJ, Dummett CO Jr, Gardiner D. The effect of virtual reality during dental treatment on child anxiety and behavior. ASDC J Dent Child. 2000 May-Jun;67(3):193-6, 160-1. 
29. Mitrakul K, Asvanund Y, Arunakul M, Paka-Akekaphat S. Effect of audiovisual eyeglasses during dental treatment in 5-8 year-old children. Eur J Paediatr Dent. 2015 Sep;16(3):239-45.

30. Agarwal N, Dhawan J, Kumar D, Anand A, Tangri K. Effectiveness of Two Topical Anaesthetic Agents used along with Audio Visual Aids in Paediatric Dental Patients. J Clin Diagn Res. 2017 Jan;11(1):ZC80-ZC83.

31. Nuvvula S, Alahari S, Kamatham R, Challa RR. Effect of audiovisual distraction with $3 \mathrm{D}$ video glasses on dental anxiety of children experiencing administration of local analgesia: a randomised clinical trial. Eur Arch Paediatr Dent. 2015 Feb;16(1):43-50.

32. Al-Khotani A, Bello LA, Christidis N. Effects of audiovisual distraction on children's behaviour during dental treatment: a randomized controlled clinical trial. Acta Odontol Scand. 2016 Aug;74(6):494-501

33. Khandelwal D, Kalra N, Tyagi R, Khatri A, Gupta K. Control of Anxiety in Pediatric Patients using "Tell Show
Do" Method and Audiovisual Distraction. J Contemp Dent Pract. 2018 Sep 1;19(9):1058-1064.

34. Shah, Harsha A., NanjundaSwamy Kv, S. Kulkarni and S. Choubey. "Evaluation of dental anxiety and hemodynamic changes (Sympatho-Adrenal Response) during various dental procedures using smartphone applications v/s traditional behaviour management techniques in pediatric patients." International journal of applied research 3 (2017): 429-433.

35. El-Sharkawi HF, El-Housseiny AA, Aly AM. Effectiveness of new distraction technique on pain associated with injection of local anesthesia for children. Pediatr Dent. 2012 Mar-Apr;34(2):e35-8.

36. Holst A, Crossner CG. Direct ratings of acceptance of dental treatment in Swedish children. Community Dent Oral Epidemiol. 1987 Oct;15(5):258-63.

37. Kilinç G, Akay A, Eden E, Sevinç N, Ellidokuz H. Evaluation of children's dental anxiety levels at a kindergarten and at a dental clinic. Braz Oral Res. 2016 Aug 18;30(1):S1806-83242016000100701. 